A C T A C H E M I A S CA N D I N A I C A 22 (1968) 1745-1756

\title{
An Improved Analysis of Adenosine Triphosphate by the Luciferase Method
}

\author{
HANS RASMUSSEN and ROBERT NIELSEN
}

\author{
Institute of Biological Chemistry, University of Copenhagen, Copenhagen, Denmark
}

\begin{abstract}
A new instrument is described for the measurement of adenosine triphosphate by the luciferase method. The advantages of the instrument are high sensitivity (at least $10^{-14}$ moles) and fast and convenient analysis. The systematic errors of the method (especially the specificity) have been investigated. If the initial flash is used for the evaluation, the systematic errors always are less than $10 \%$. It is concluded that the signal following the initial flash is of very limited value for the measurement. Improvement of the specificity of the analysis by use of enzyme preparations purified by gel filtration is also described.
\end{abstract}

The observation by McElroy ${ }^{1}$ that the luminescence of extracts of fireflies 1 depends on the concentration of ATP * has been utilized for sensitive and convenient analytical methods for ATP (reviews, e.g., Refs. 2 and 3) and of related compounds. ${ }^{3-5}$ The various types of instruments used for measuring the luminescence have been reviewed by Chase. ${ }^{6}$ Recently a liquid scintillation counter ${ }^{7}$ and a commercial photometer ${ }^{8}$ have been adapted to the light measurement.

The crystalline luciferase is specific for ATP (e.g. Ref. 2), but the crude extracts of fireflies most commonly used for analytical purposes will also show luminescence when supplied with ADP or NTP because of the presence of adenylate kinase (E.C. 2.7.4.3.) and NDP kinase (E.C. 2.7.4.6.) in the extract. This lack of specificity might be a serious limitation of the applicability of the method and the use of partially purified preparations of luciferase will improve the method. ${ }^{2,3}$,

This paper describes a new instrument for the measurement of the luminescence. The advantages of the instrument are high sensitivity, fast and convenient analysis, and increased specificity with crude enzyme extracts. The use of enzyme preparations purified by gel filtration ${ }^{9}$ for improved specificity is also described.

\footnotetext{
* Abbreviations: ADP, adenosine diphosphate; AMP, adenosine monophosphate; ATP, adenosine triphosphate; d-ATP, 2-deoxy-adenosine triphosphate; CTP, cytosine triphosphate; GTP, guanosine triphosphate; ITP, inosine triphosphate; NDP, nucleoside diphosphate; NTP, nucleoside triphosphate; UTP, uridine triphosphate.
} 


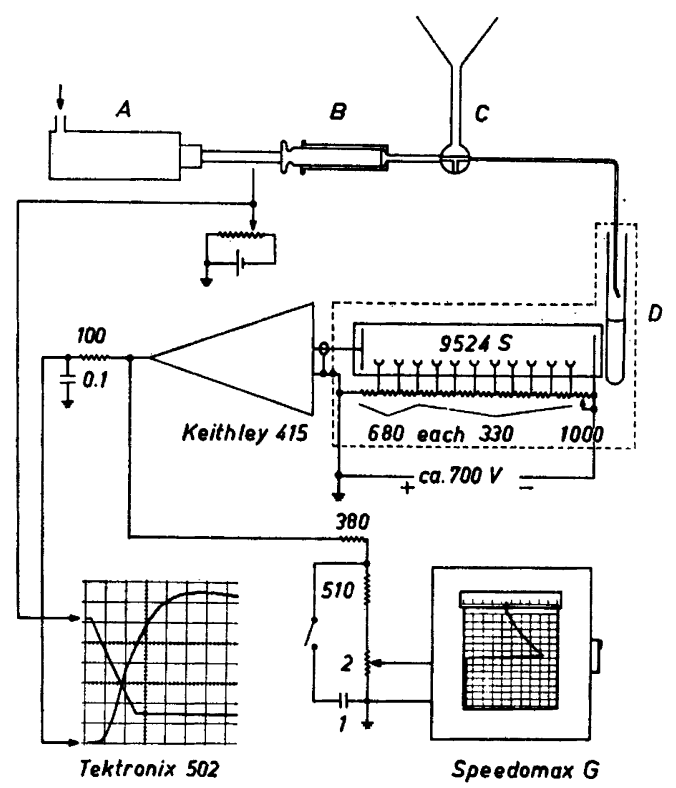

Fig. 1. Diagram of the instrument used for measurement of the luminescence. A, singleacting air cylinder. B, $1 \mathrm{ml}$ glass syringe. C, stopcock. D, cuvette housing. All resistance values are in kilohms, and capacitance values in $\mu \mathrm{F}$. The oscillographic record is an ATP flash ( $2 \times 10^{-10}$ moles ATP); abscissa: 1 large division $=0.2$ sec; ordinate: 1 large division $=10^{-8} \mathrm{amp}$.

\section{METHODS}

The instrument. Fig. 1 shows a diagram of the instrument used for measuring the luminescence. The single-acting air cylinder (A) was connected to the air line via a threeway-valve and a self-bleed pressure regulator (not shown). The piston would move the plunger of a $1 \mathrm{ml}$ glass syringe (B) and thereby inject the enzyme solution into the cuvette. The syringe could be filled with enzyme solution from the funnel via the stopcock (C) (Fisons Scientific Apparatus Ltd., Loughborough, England). The needle (internal diameter about $0.6 \mathrm{~mm}$ ) leading into the cuvette housing (D) was bent slightly to allow fast injection of the enzyme. The proper injection time was obtained by adjusting the length of the polyethylene tube connecting the stopcock and the needle, and the pressure of the air leaving the pressure regulator.

The electronic arrangement used for recording the light intensity consisted of the photomultiplier, the amplifier and the recorder. The photomultiplier (9524 S or B, EMI Electronics Ltd., Hayes, England) was supplied with a high voltage from batteries and operated with a sensitivity of about 5 A/lumen. Optimal signal-to-noise ratio was ob. tained by adjusting the 1 megohm potentiometer controlling the potential of the first dynode. It might, however, be exchanged by a fixed resistor. A micro-micro ammeter (type 415, Keithley Instruments Inc., Cleveland, Ohio) with a response time less than $10 \mathrm{msec}$ was used as an amplifier. The output from the amplifier was filtered and recorded on a $2 \mathrm{mV}$ potentiometric recorder with a rise time of $0.25 \mathrm{sec}$ (Speedomax G, Leeds \& Northrup Co., Philadelphia, Pennsylvania). Faster recording could be obtained on the oscilloscope (type 502, Tektronix Inc., Beaverton, Oregon). The readability of the oscilloscope trace was increased by the small RC-filter. The movement of the plunger of the syringe could be followed on the oscilloscope by means of the potentiometer coupled to the piston of the air cylinder. 
The cuvette housing is shown in Fig. 2. The photomultiplier (cross-hatched) was shielded with a mu-metal shield (EMI) which was kept at cathode potential and covered with insulating tape. It was held in a cylindrical tube between the socket and a teflon ring, the opening of which was covered with a celluloid window (not hatched). The socket was mounted in a cylindrical cap containing the dynode resistors and the connectors and forming a light-tight fit with the outer tube in such a way that the position of the photomultiplier could be adjusted. The cuvette (not hatched) was located in a hole in a cylinder which could be turned in an outer cap between two stops by means of a handle. The most convenient position of the handle should be found by trial and not taken from the drawing. In one extreme position the cuvette would be in front of the photomultiplier (section $\mathrm{C}-\mathrm{C}$ ) and in the other position the cuvette could be removed through a hole in the side of the outer cap. The housing was mounted in such a way that the cuvette was turned in a vertical plane with the two extreme positions at an equal distance from the vertical.

Performance of the analysis. The cuvettes were soft glass test tubes $(7.5 \times 70 \mathrm{~mm})$ which were selected to give the same height of the same content of water. They were cleaned in hot sulphuric acid containing a little potassium nitrate, and carefully rinsed with water. In this way any adsorbed ATP was removed.

The time used for injection of the enzyme was critical for mixing and measurement of the flash height. It should be as constant as possible, and the pneumatic system was excellent for this purpose. Many configurations of the needle and cuvette were tried. With the present system long injection times $(1.5 \mathrm{sec})$ would result in poor mixing. The sample would move up in the cuvette as a luminescent band and give rise to a spike on the flash curve. Short injection times (about $0.2 \mathrm{sec}$ ) had the effect that the enzyme solution was ricocheted from the cuvette. An injection time of about 0.4 sec was chosen. The mixing of enzyme (in all experiments $800 \mu \mathrm{l}$ ) and sample $(10-200 \mu \mathrm{l}$ ) was quite good with this injection time. The mean of the sample concentrations at the top was higher than $90 \%$ of the mean of the concentrations at the bottom of the cuvette (10

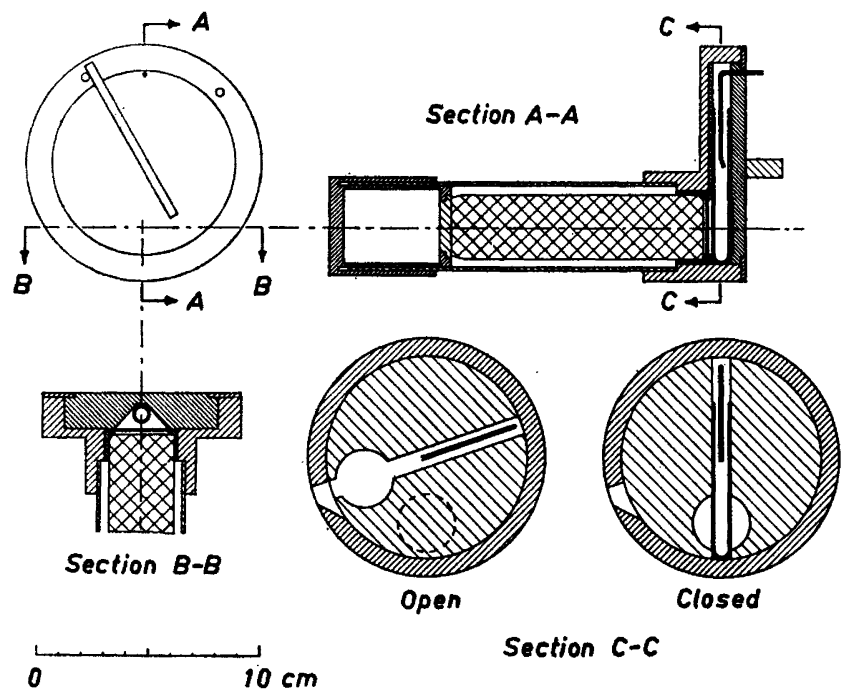

Fig. 2. Construction details of the cuvette housing. For further description see the section METHODS.

Acta Chem. Scand. 22 (1968) No. 6 
exp.). The standard deviation on a single concentration (bottom or top) was about $\pm 3 \%$ (10 exp.) or 5-10 times the standard deviation on the volume of sample (Carlsberg constriction pipettes). Some variation of the degree of mixing could be tolerated because the photomultiplier was exposed to light from about $80 \%$ of the enzymesample mixture.

\section{MATERIALS}

Preparation of crude enzyme extract. $100 \mathrm{mg}$ desiccated firefly tails (Stock No. FFT, Sigma Chemical Company, St. Louis, Missouri) were ground with a little sand (Merck, Darmstadt, Germany) and $2 \mathrm{ml}$ buffer (0.1 M glycyl-glycine with $1 \mathrm{mM}$ EDTA, pH 7.7). The suspension was centrifuged at $35000 \mathrm{~g}$ for $30 \mathrm{~min}$ at $4^{\circ} .80-90 \%$ of the activity was contained in the supernatant fluid which kept at $-25^{\circ}$ was stable for many months.

The extract of $100 \mathrm{mg}$ firefly tails was used diluted in $100 \mathrm{ml}$ buffer containing 50 $\mathrm{mM}$ glycine, $10 \mathrm{mM} \mathrm{Na} \mathrm{HAsO}_{4}, 1 \mathrm{mM}$ EDTA, and $5 \mathrm{mM} \mathrm{MgSO}$ (pH 7.7) (cf. Ref. 10). This buffer inhibits the flash with ATP about $15 \%$ compared with the signal obtained in the glycyl-glycine buffer normally employed.2 It was, however, inexpensive and rather inhibitory to microbial contamination. The diluted enzyme could be stored for some weeks at $-25^{\circ}$ with less than $35 \%$ loss of activity.

Chemicals. Nucleotides were obtained from C. F. Boehringer \& Soehne, Mannheim, Germany and from Sigma Chemical Company and made up in aqueous solutions (20 mM) which were stored frozen. ADP was purified (especially from ATP) by ion-exchange chromatography ${ }^{11}$ on Dowex 1 (chloride form, $X 2,200-400$ mesh, $13 \mathrm{~cm}$ column) eluted with a linear gradient of water to $250 \mathrm{mM} \mathrm{NaCl}+10 \mathrm{mM} \mathrm{HCl}$.

Other chemicals were analytical grade. Deionized water was used throughout.

\section{RESULTS}

The ATP flash. Included in Fig. 1 is an oscillographic record of the ATP flash and the simultaneously recorded flow trace. The maximal light level was reached in about 1 sec after the start of the injection, and the photocurrent equivalent to this maximal light level was called the flash height. It could easily be read from the Speedomax record (chart speed 6" $/ \mathrm{min}$ ). The decline of light intensity after the maximum was due to product inhibition of the enzyme system and enzymatically catalyzed hydrolysis of the pyrophosphate formed in the luciferase reaction (e.g., Ref. 2).

The flash height was found to be linearly related to the amount of ATP present in the cuvette, when this was varied between $10^{-14}$ and $10^{-9}$ moles, the upper limit being set by the maximal anode current allowed for the photomultiplier (about $3 \mu \mathrm{A}$ ).

Since the enzyme as well as both substrates were diluted with the sample, the flash height was found to be inversely proportional to the total volume raised to between second and third power. Identical volumes of samples and standards were consequently used in a series of measurements.

The accidental error of the analysis was primarily determined by the error of the pipetting of the sample (below $1 \%$ ), by the shot noise of the photomultiplier, and by the variation in mixing of sample and enzyme. The relative standard error on a single analysis calculated from 10 analyses was typically $\pm 1 \%\left(2 \times 10^{-11}\right.$ moles ATP $)$ and $\pm 2 \%\left(2 \times 10^{-12}\right.$ moles ATP $)$ (blank negligible $)$. According to the specifications of the manufacturer the gain of the photomultiplier was about $10^{5}$. The bandwidth of the Speedomax recording system 
was estimated to about $5 \mathrm{~Hz}$ * $^{*}$ On the basis of this the dashed curve of Fig. 5 was calculated ( $c f$. Ref. 12) showing the root mean square (rms) shot noise of the photomultiplier as a function of the ATP present in the sample (blank value equivalent to $10^{-13}$ moles ATP and typical activity of the enzyme). The accidental error of the analysis was considerably higher than the rms value of the shot noise. In some cases the peak-to-peak value of the noise can be obtained by multiplying the rms value by a factor as high as 8 (e.g., Ref. 13). For this reason it was difficult to establish whether or not the total error of the analysis was primarily caused by the shot noise. It appeared, however, that the accidental error of the analysis amounted to about 2 times the calculated shot noise. It was, however, always higher than about $\pm 1 \%$ because of the other factors influencing the accuracy.

Sensitivity of the method. The sensitivity of the method was limited by the blank value and activity of the enzyme and by the design of the instrument.

The blank value of the enzyme was caused by ATP present in the firefly tails and by ATP formed by microorganisms in the diluted enzyme extract. The simplest way to remove the ATP was to age the diluted enzyme at room temperature or the concentrated enzyme at $4^{\circ}$ for some time. Magnesium sulphate should be added to the concentrated enzyme. Freshly diluted crude enzyme showed a flash corresponding to about $10^{-11}$ moles ATP. In some hours this content was decreased to about $10^{-12}$ moles, while ageing overnight resulted in a blank value of about $2 \times 10^{-13}$ moles ATP. The activity of the enzyme extracts as measured by the flash height of a certain amount of ATP was never decreased more than $15 \%$ during the ageing.

A part of the ATP present in the diluted enzyme originated from microorganisms or was adsorbed to particles in the extract. This "bound" ATP amounted to more than the "free" ATP, especially in the aged extracts. The aged systems furthermore appeared to reach a steady state equilibrium between breakdown and synthesis of ATP. A part of the "bound" ATP was made available for the luciferase by shaking the aged enzyme or by injection of enzyme into the cuvette. This resulted in a blank flash of almost the same appearance as an ATP flash. It was found difficult to reproduce this blank flash accurately. Enzyme extracts which were heavily contaminated with microorganisms would in some cases exhibit anaerobiosis of the solution in the flow system of the instrument. A high initial spike on the flash would result from injection of an anaerobic enzyme system ( $c f$. Ref. 14).

Fig. 3. Sensitivity of the method. Diluted crude enzyme extract was aged under sterile conditions at room temperature overnight. For obtaining the oscillographic records shown, the time constant of the input filter (Fig. 1) was increased ten times.

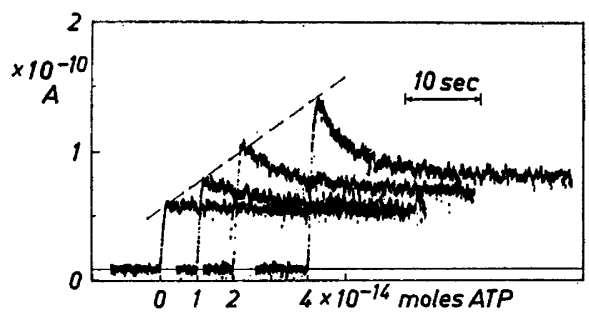

* The flashes reproduced in this paper are oscillographic records which, with the exception to Fig. 3, were obtained with a recording system having a bandwidth of about $25 \mathrm{~Hz}$. The signalto-noise ratio is about 3 times lower than the one measured on the Speedomax records.

Acta Chem. Scand. 22 (1968) No. 6 


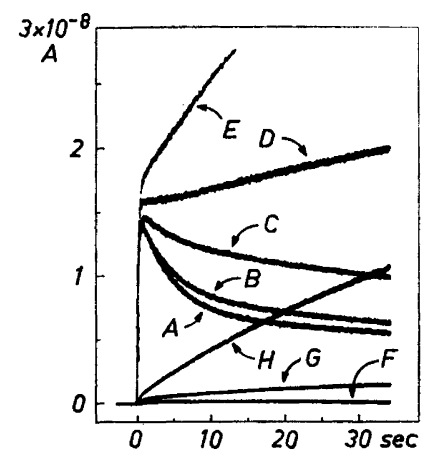

Fig. 4. Effect of ADP upon the ATP flash. Diluted crude enzyme extract was aged overnight in the centrifuge tube (see the section Sensitivity of the method). Composi-

\begin{tabular}{ccc}
\multicolumn{3}{c}{ tion of the samples: } \\
Curve & $10^{-11}$ & $10^{-11}$ \\
& moles ATP moles ADP
\end{tabular}

$\begin{array}{rrr}\text { A } & 2 & \\ \text { B } & 2 & 2 \\ \text { C } & 2 & 20 \\ \text { D } & 2 & 60 \\ \text { E } & 2 & 100 \\ \text { F } & & 2 \\ \text { G } & & 20 \\ \text { H } & & 60\end{array}$

Several procedures were tried to further reduce the blank value. Spinning down the microorganisms in the diluted enzyme and then ageing it in the centrifuge tube without mixing up the precipitate was partially effective. When sensitive measurements were made, the diluted crude enzyme was filtered through Millipore filters (1.2 $\mu$ pore size with prefilter followed by sterile $0.45 \mu$ pore size ${ }^{15}$ ). It is not advisable to filter the concentrated enzyme extract because too much is lost in the filter adapter. By filtering and ageing overnight under sterile conditions the blank value of the diluted extract could be lowered to about $2 \times 10^{-14}$ moles as shown in Fig. 3. With such enzyme extracts the presence of at least $10^{-14}$ moles ATP could be significantly established. Similar results could be obtained by gel filtration of the concentrated enzyme extract on a Sephadex G-25 column.9 This procedure was advantageous also for removing other low molecular weight substances from the enzyme extract.

Systematic errors. Specificity of the method. A serious systematic error is the lack of specificity when the crude enzyme extract is used. ADP will interfere with the system in two ways, namely as substrate for adenylate kinase and as one of the two substrates for NDP kinase. In both cases ATP will be formed. In Fig. 4 the flash obtained with $2 \times 10^{-11}$ moles ATP is compared with the flash given by this amount in combination with various amounts of ADP. When a certain ADP/ATP ratio was exceeded the flash height could no longer be read. The highest ADP/ATP ratios which would allow reading of the flash height in many experiments with different concentrations and different preparations of enzyme were found to increase the flash height less than $10 \%$. If the flash showed decline, the increase was less than about $5 \%$. The rate of ATP formation catalyzed by adenylate kinase has under some conditions been found to be proportional to the second power of the concentration of ADP. ${ }^{16}$ This implies that the highest ADP/ATP ratio which permits reading of the flash height can be increased by dilution of the sample. Fig. 5 shows the highest permissible ADP/ATP ratios (open circles) as function of the amount of ATP which was analyzed. A 10-fold dilution of a sample would increase the highest permissible ADP/ATP ratio about 3 times. 
ADP was, however, observed to exert an additional effect upon the ATP flash. When ATP was analyzed in combination with ADP (Fig. 4), the decline of the flash was inhibited, but the inhibition could not be accounted for by the luminescence caused by ADP alone. The decline was inhibited significantly even by quantities of ADP giving rise to a luminescence which was too small to be detected with the sensitivity employed (Fig. 4, curves B and F). The inhibition of the decline was most likely due to inhibition by ADP of inorganic pyrophosphatase (E.C. 3.6.1.1.) which is known to cause the decline.2,14 In the assay of inorganic pyrophosphatase according to Heppel ${ }^{17}$ (liberation of inorganic phosphate from $1.4 \mathrm{mM}$ pyrophosphate), ADP (2.2 $\mathrm{mM}$ ) was found to inhibit the enzyme of crude firefly extract about $35 \%$. Control experiments showed no phosphorylation or dephosphorylation of ADP under these conditions.

As seen from Fig. 4 the extent of inhibition of the decline was determined by the ADP/ATP ratio. The sensitivity to ADP was, however, dependent upon the amount of ATP to be analyzed, partly because the decline of the flash differed for different concentrations of ATP (Table 1). The decline of the ATP flash was consistently found to be minimal in the region around $5 \times 10^{-10}$ moles. This is probably a consequence of the reaction mechanism of luciferase and inorganic pyrophosphatase. At low concentrations of ADP the inhibition of the decline was not fully developed, and when the decline was minimal high concentrations of ADP had almost no effect (Table 1). The effect described might be expected to vary somewhat for different preparations of enzyme, depending for instance on the relative activity of luciferase and inorganic pyrophosphatase. On ageing, the content of ADP in the diluted enzyme extract was lowered in parallel with the content of ATP. This could be judged from the luminescence given by NTP alone. The ATP flash was found to decline faster in the aged extracts than in the fresh and the decline in the aged extracts was also more sensitive to ADP. ADP/ATP ratios as low as 0.1 would in some cases inhibit the decline significantly.

The flash height was slightly increased by small amounts of ADP (Fig. 4, curve C). It is likely that some decline in light intensity occurred during the time used for mixing and full development of the flash. When the decline was inhibited by ADP, the flash height would therefore be increased. The small

Table 1. Effect of ADP on the decline of the ATP flash. Crude enzyme was aged overnight at room temperature. The ADP + ATP flashes were corrected for the luminescence given by ADP alone.

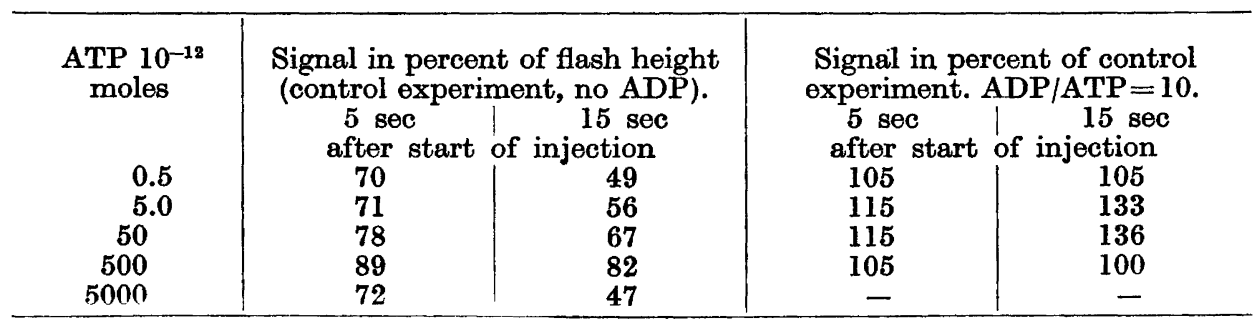

Acta Chem. Scand. 22 (1968) No. 6 


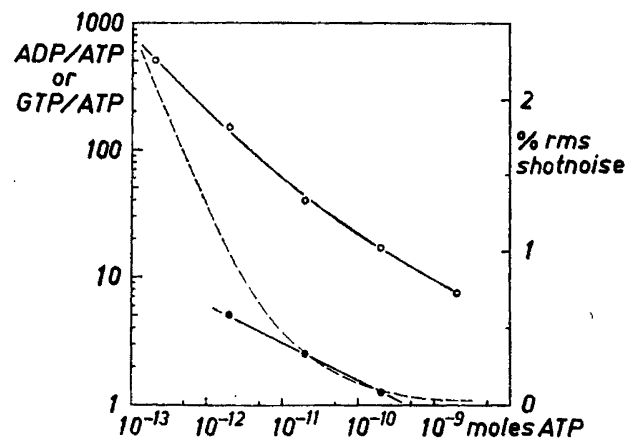

Fig. 5. Correlation between amount of ATP and the highest $A D P / A T P$ ratio (open circles) or GTP $/ A T P$ ratio $(\mathrm{ADP}=\mathrm{GTP}$, filled circles) which would allow reading of the flash height. Crude enzyme extract was aged overnight at room temperature. Dashed curve (right hand scale): Calculated rms shot noise as function of the amount of ATP to be analyzed (blank value equivalent to $10^{-18}$ moles ATP).

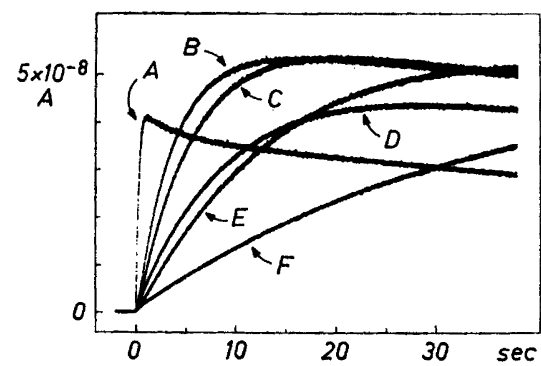

Fig. 6. Luminescence produced by NTP. Crude enzyme aged overnight at room temperature. A, $7 \times 10^{-11}$ moles ATP. B, GTP + ADP. C, ITP + ADP. D, d-ATP + ADP. E, UTP + ADP. F, CTP + ADP. $2 \times 10^{-10}$ moles NTP $+2 \times 10^{-10}$ moles ADP.

initial luminescence given by ADP (Fig. 4, curves $\mathrm{G}$ and $\mathrm{H}$ ) was probably not due to ATP or other NTP present in the freshly prepared solution of ADP. This initial luminescence was not linearly related to the concentration of ADP, but showed a saturation dependence. There was some indication that the effect was confined to unsterile enzyme extracts. It is possible that the luminescence was caused by NTP liberated from microoroganisms in the enzyme or that ADP caused desorption of ATP bound to components in the enzyme extract.

In Fig. 6 is shown the luminescence given by some NTP in combination with ADP. The appearance of these flashes was determined by the rate of ATP formation catalyzed by NDP kinase and by the inhibition of the luciferase reaction. The maximal luminescence was obtained several seconds after the peak of the ATP flash. The absolute value of this maximal luminescence and the initial rate of light production was roughly proportional to the amount of NTP present for a certain concentration of ADP. The relationship between maximal luminescence and concentration of ADP was more complicated because of the effects of this compound described above and because of the content of ADP in the crude enzyme extract (of the order of $10^{-13}-10^{-12}$ moles $/ 800 \mu \mathrm{l}$ ).

The specificity problem with respect to NTP might be treated in the same way as above. With a certain NTP/ATP ratio the flash height could still be read (Fig. 7), and the increase in flash height was in many experiments found to be less than $10 \%$, even for GTP which was the fastest reacting NTP. The highest permissible GTP/ATP ratios (GTP $=$ ADP) are shown in Fig. 5 (filled circles). A 10-fold dilution of a sample would increase this ratio about twice. Higher ratios might be expected for other NTP or for lower ADP/NTP ratios. 
It should be noted that the highest permissible GTP/ATP ratio amounted to less than one tenth of the highest permissible ADP/ATP ratio. The two series of experiments shown in Fig. 5 were obtained with the same preparation of crude enzyme. Other preparations gave values of the same order of magnitude.

In summary, the systematic errors caused by the lack of specificity of the crude enzyme extracts were found to be less than $10 \%$ if the flash height could be read. The nature of contamination causing the interference was without influence upon this maximal systematic error. Dilution of a sample of unknown composition would decrease the relative influence of interfering compounds, but most likely increase the accidental error of the analysis (Fig. 5). The part of the light signal following the initial flash was influenced by so many factors that it was of no value for analysis of ATP in any complex sample.

Analysis with partially purified enzyme. By gel filtration of the crude enzyme extract ${ }^{9}$ it was possible to decrease the activities of the two enzymes affecting the specificity of the analysis. The luciferase was well separated from the adenylate kinase and for routine purposes only the positions of NDP kinase and luciferase in the chromatogram was established by assays. To a part of the luciferase peak containing sufficiently little NDP kinase, an equal part of the luciferin peak was added and the total volume adjusted to correspond with $1 \mathrm{mg}$ firefly tails per $\mathrm{ml}$ buffer. Although the total recovery of the enzyme in the gel filtration was about $50 \%$, the purified extracts obtained in this way showed an equal or sometimes even higher activity (ATP flash)

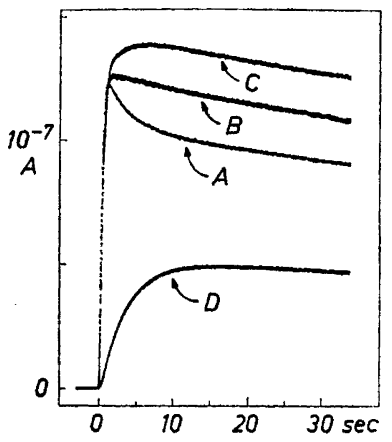

Fig. 7. Effect of GTP + ADP upon the ATP flash. Crude enzyme aged overnight at room temperature. Composition of the samples:

$\begin{array}{cccc}\text { Curve } & \text { ATP } & \begin{array}{c}10^{-10} \text { moles } \\ \text { ADP }\end{array} & \text { GTP } \\ & & & \\ \text { A } & 2 & 2 & \\ \text { B } & 2 & 2 & 2 \\ \text { C } & 2 & 3 & 3 \\ \text { D } & & 3 & 3\end{array}$

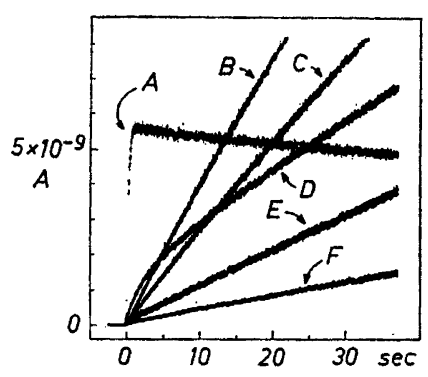

Fig. 8. Luminescence produced by NTP. The experiment was performed with a purified preparation obtained by gel filtration of the crude enzyme used in the experiment depicted in Fig. 6. A, $6 \times 10^{-12}$ moles ATP. B, GTP + ADP. C, ITP + ADP. D, d-ATP + ADP. E, UTP + ADP. F, CTP + ADP. $2 \times 10^{-10}$ moles NTP + $2 \times 10^{-10}$ moles ADP. The trace given by UTP was corrected for the presence of $1.5 \times 10^{-12}$ moles ATP. 
than the corresponding crude enzyme (cf. Figs. 6 and 8). This was probably due to removal of inhibitory dehydroluciferin during the gel filtration.

The preparation used in the experiments depicted in Fig. 8 was obtained by gel filtration (Sephadex G-10 and G-100 combined) ${ }^{9}$ of the crude enzyme extract used in the experiments shown in Fig. 6. $50 \%$ of the luciferase peak was used. Inorganic pyrophosphatase was partially removed in the gel filtration, and the ATP flash was not inhibited in the purified enzyme. The difference between the crude and purified enzyme in this experiment was rather small, but the decline with crude enzyme might have been somewhat inhibited by ADP present in the extract ( $c f$. Fig. 4, curve A). The effect of purification was, however, clearly reflected in the constant rates of light production caused by NTP together. with ADP.

The blank values of partially purified preparations were equivalent to between 1 and $2 \times 10^{-14}$ moles ATP and the content of ADP was also very low. By gel filtration the content of adenylate kinase was lowered about 500 times as judged from the rate of light formation from ADP. ADP $\left(2 \times 10^{-8}\right.$ moles) would cause a formation of about $10^{-13}$ moles ATP per sec with the purified preparations while the crude enzymes gave about $5 \times 10^{-11}$ moles ATP per sec. The NDP kinase was removed less effectively when $50 \%$ of the luciferase peak was used. A decrease of about 50 fold of the activity of the crude enzyme was obtained (Figs. 6 and 8). The highest permissible ADP/ATP ratio was increased about 50 times and the highest GTP/ATP ratio about 10 times. It is interesting to note that all of the NTP tried (except d-ATP) showed the same relative initial rates of light formation in the crude and purified enzyme. This suggests a single enzyme to be responsible for the formation of ATP from NTP and ADP. It is very unlikely that the flash obtained with d-ATP (Figs. 8, curve D) was caused by impurities of ATP. The compound might affect the activity of luciferase or undergo some additional reaction.

\section{DISCUSSION}

The instrument was designed for fast and convenient analysis of ATP, but the design could be modified in several ways. The high pressure of the enzyme solution in the syringe and stopcock during the injection might be avoided by a modified pneumatic system (e.g. a double-acting air cylinder with controlled speed). The choice of stopcock would thereby become less critical. A transistorized operational amplifier could be built into the instrument housing, but the calibrated gain setting should be maintained. It is extremely useful because the analysis covers a very wide range of concentrations. If the instrument is to be used under conditions of high humidity, a desiccant should be placed in the photomultiplier compartment. The geometry of the cuvette-photocathode system can be optimized further with respect to mixing time, gain of light and dark noise of the photomultiplier (coolable housing), but probably not without sacrifice of simplicity in operation and in choice of cuvettes.

In, fact the sensitivity of the analysis was not limited by the instrument, but by the contamination of the luciferase with ATP. The most critical part of this ATP was definitely that which originated from microorganisms and it 
is essential to avoid microbial growth during ageing of the enzyme as well as during the storage in the flow system of the instrument. This system must therefore be built to allow effective cleaning. Antibiotics were not effective in preventing microbial contamination. The minimal amount of ATP which could be detected was at least $10^{-14}$ moles corresponding to a concentration of about $5 \times 10^{-11} \mathrm{M}$. Seliger and McElroy ${ }^{2}$ report accurate measurement of ATP in concentrations of the order of magnitude of $10^{-9} \mathrm{M}$. The sensitivity of the analysis might be increased by use of more concentrated enzyme solutions. The concentration employed in the present work represents a compromise between sensitivity and economy. The luciferase system is very sensitive to some salts, ${ }^{3}$ but because of the high sensitivity of the analysis, interference of this type can be reduced considerably by dilution of the samples.

The investigation of the systematic errors of the analysis clearly establishes the flash height as the most reliable basis for measurement of ATP. Some systematic errors (e.g. salt inhibition) can be revealed by use of internal standards, but those caused by lack of specificity are more difficult to control, although the shape of the flash curve might indicate such interference. This does not solve the problem arising if a sample gives a flash which differs from the flash of a standard. The shape of this latter will furthermore depend on the amount which is analyzed.

A lack of specificity of a method of analysis might become critical only in some applications. In general the present analysis is most likely to be affected by ADP which is almost bound to be present in biological systems containing ATP. The interference is also possible if a compound is to be measured by enzymatically catalyzed formation of ATP from ADP (e.g. phosphoenolpyruvate). Gel filtration is, however, quite effective in removing the adenylate kinase. On the other hand the interference from NTP is somewhat more crucial because it depends not only on the concentration (and nature) of NTP, but also on the amounts of ADP present in the sample and the luciferase. The degree of specificity which can be obtained with the purified enzyme (50\% luciferase used) is, however, probably sufficient to allow analysis of ATP in almost any biological system. The purified enzyme offers some additional advantages. The blank value is very low, and if the inorganic pyrophosphatase is removed from the luciferase, the ATP flash will exhibit very small decline, thus making possible measurement of the light intensity over a long period of time. The signal-to-noise ratio will thereby be increased.

A sensitive analysis of ATP can be used for sensitive analyses of compounds which can undergo reactions involving ATP. ${ }^{3,4,9}$ Preliminary fractionation of samples might be necessary. For instance NTP after fractionation might be analyzed with NDP kinase and luciferase or by the rate of light production with partially purified luciferase. ADP is readily analyzed as ATP after incubation with pyruvate kinase (E.C. 2.7.1.40.) and phosphoenolpyruvate (e.g. Ref. 18). In this laboratory concentrations of the order of $10^{-9} \mathrm{M}$ phosphoenolpyruvate have been analyzed as ATP after incubation with pyruvate kinase and ADP. ATP present in the samples was removed by adsorption onto activated charcoal. 
Acknowledgements. The construction of instruments by Mr. P. Korsgaard and Mr. $\mathbf{P}$. Hansen is gratefully acknowledged. This investigation was supported by grants from Carlsbergfondet, Denmark.

\section{REFERENCES}

1. McElroy, W. D. Proc. Natl. Acad. Sci. U.S. 33 (1947) 342.

2. Seliger, H. H, and McElroy, W. D. Light: Physical and Biological Action, Academic, New York 1965, p. 176 and p. 367.

3. Strehler, B. L. In Bergmeyer, H. U. Methods of Enzymatic Analysis, Academic, New York 1963, p. 559.

4. Strehler, B. L. and Totter, J. R. Arch. Biochem. Biophys. 40 (1952) 28.

5. Strehler, B. L. and Totter, J. R. Methods Biochem. Anal. 1 (1954) 341.

6. Chase, A. M. Methods Biochem. Anal. 8 (1960) 61.

7. Addanki, S., Lotos, J. F. and Rearich, P. D. Anal. Biochem. 14 (1966) 261.

8. Prydz, H. and Frøholm, L. O. Acta Chem. Scand. 18 (1964) 554.

9. Nielsen, R. and Rasmussen, H. Acta Chem. Scand. 22 (1968) 1757.

10. Strehler, B. L. and McElroy, W. D. In Colowick, S. P. and Kaplan, N. O. Methods in Enzymology, Academic, Now York 1957, Vol. 3, p. 871.

11. Munch-Petersen, A. and Neuhard, J. Biochim. Biophys. Acta 80 (1964) 542.

12. Rodda, S. Photo-Electric Multipliers, MacDonald and Co., London 1953, p. 102.

13. Chance, B. Rev. Sci. Instr. 22 (1951) 619, p. 625.

14. McElroy, W. D. and Seliger, H. H. In McElroy, W. D. and Glass, B. Light and Life, The Johns Hopkins Press, Baltimore 1961, p. 237.

15. Application Data Manual ADM-20, Millipore Filter Corporation, Bedford, Massachusetts 1963 , p. 11.

16. Noda, L. In Boyer, P. D., Lardy, H. and Myrbäck, K. The Enzymes, Academic, New York 1962, Vol. 6, p. 144.

17. Heppel, L. A. In Colowick, S. P. and Kaplan, N. O. Methods in Enzymology, Academic, New York 1955, Vol. 2, p. 570 .

18. Holmsen, H., Holmsen, I. and Bernhardsen, A. Anal. Biochem. 17 (1966) 456.

Received December 22, 1967. 